\title{
THE HYDROSTATIC REDUCTION OF INTUSSEPTION IN 60 PAEDIATRIC AGE GROUP- OUR EXPERIENCE
}

\author{
P. S. Mishrikotkar' ${ }^{1}$ R. J. Totla ${ }^{2}$, Mohd. Ajaz ${ }^{3}$, Haseeb ${ }^{4}$, Jyoti Rai ${ }^{5}$
}

\section{HOW TO CITE THIS ARTICLE:}

P. S. Mishrikotkar, R. J. Totla, Mohd Ajaz, Haseeb, Jyoti Rai. “Non surgical reduction of Intussusception”. Journal of Evolution of Medical and Dental Sciences 2013; Vol2, Issue 32, August 12; Page: 6135-6142.

INTRODUCTION: Intussusception is a common cause of childhood intestinal obstruction, occurring more frequently in children aged 6 months to 2 years and in more males than in females. When this condition occurs in neonates and in children older than 2 years, there is a high incidence of associated bowel abnormality that serves as an initiating lead point for intussusception.

KEYWORDS: Intussusception, ultrasound, Hydrostatic reduction.

Intussusception is a common abdominal emergency in infants and children. A lot of debate exists regarding the best method for diagnosis and treatment. In our set up, most children with intussusception come to us late and only a few satisfy the criteria for non-operative hydrostatic reduction. Whenever hydrostatic reduction of intussusception is feasible, barium enema has been considered the gold standard. However recently, alternative methods using air, oxygen and ionic water soluble iodinated contrast media have been reported.

US have occasionally been used for the past five years in our institution to diagnose intussusception when the clinical features were not clear cut. Having gained experience with US in diagnosing intussusception, we tried hydrostatic reduction of childhood intussusception using water under US guidance, with the idea of reducing exposure to radiation, lessening absorption of radiation by the contrast media and decreasing potential peritoneal contamination in the event of iatrogenic perforation during attempted reduction

Sub: Hydrostatic reduction of acute intestinal Intussusception in paediatric age group over surgery.

MATERIAL \& METHOD: 64 paediatric age group patients referred for pain, vomiting, and bloody stools. High frequency probe USG done on Philips iU22 Ultrasound system using 3,5,12 MHz probes. USG showed bowel in bowel appearance in various quadrant of abdomen. Selection of patient on various criteria's for hydrostatic reduction. Patients with appendicular inflammation, Meckel's, obstruction, free fluid in peritoneal cavity excluded.

Table 1:

\begin{tabular}{|c|c|c|c|}
\hline Patients & S/o obstruction /Mass & Hydrostatic reduction & Operations \\
\hline 64 & 4 & 60 & 4 \\
\hline
\end{tabular}


METHOD FOR REDUCTION- Foley's bulb inserted per rectally, Normal saline/ ringer lactate used, wide bore IV set used, USG guidance to see for water movement upto the intussusception, till reduction achieved. Follow up after 24 hrs \& 5 days. Patient was kept NBM for 24 hrs following procedure \& IV antibiotics given for 5 days.

Result: All 60 patients who undergone hydrostatic reduction well tolerated the procedure. All went home uneventfully.

The four distinct findings on US suggesting successful reduction were:

a. Disappearance of the intussusceptum,

b. Visualisation of reflux of water and air bubbles through the cecum and ascending colon into the ileum through the ileocecal valve

c. Demonstration of water distended ileum and

d. Absence of intussusceptum noted during the post-evacuation US examination.

The absolute contraindications to hydrostatic reduction are:

1. Severe dehydration

2. Marked abdominal distension

3. Clinical features of peritonitis or demonstration of free intraperitoneal air on a plain abdominal radiograph.

Relative contraindications are:

1. History longer than 48 hours

2. Extremes of age - patient less than three months of age or more than two years

3. Dehydration more than five percent.

4. Small bowel obstruction on plain radiographs

5. US demonstration of a thick irregular rim of the target measuring more than $10 \mathrm{~mm}$

6. Absent Doppler signal on a color Doppler signifying non-viable bowel .

7. Ultrasonic demonstration of a lead point.

Images - 1 A \& B - intussusception pre \& post hydrostatic reduction.

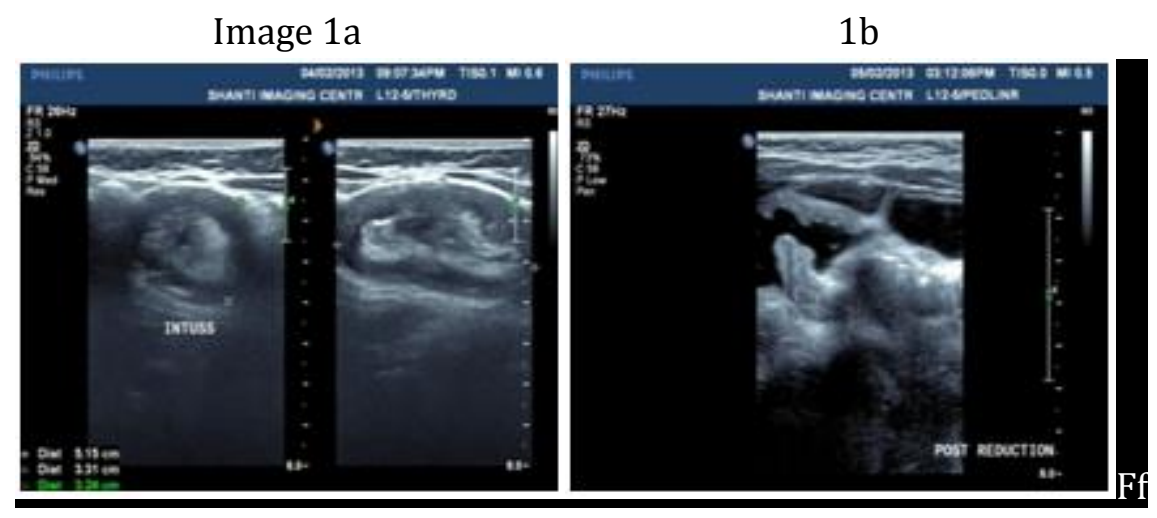




\section{STUDY CASES}

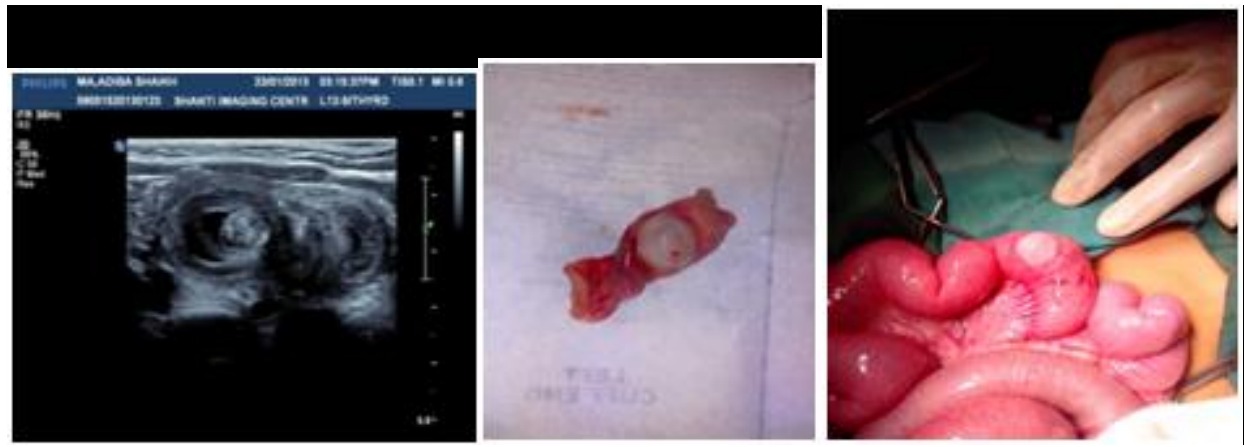

Fig.2: cystic mass causing intussusception. Operative specimen

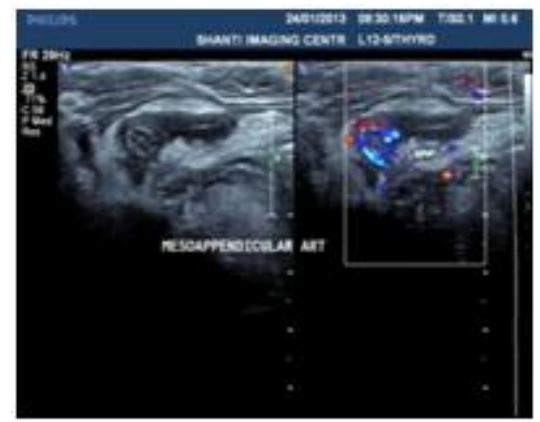

Fig 3: Intussusception sec. to appendicular pathology, surgery performed.

\section{DISCUSSION:}

Intussusception: The telescoping of a segment of bowel (the intussusceptum) into another, usually more distal, segment of bowel (the intussuscipiens).

Intussusception is a common cause of childhood intestinal obstruction, occurring more frequently in children aged 6 months to 2 years and in more males than in females, known to occur with greater frequency in children who have h/o gastroenteritis, undergone recent abdominal surgery, either intraperitoneal or retroperitoneal operations. It is an important cause of an acute abdomen in children. It occurs when one segment of bowel is pulled into itself (or a neighbouring loop of bowel) by peristalsis. Intussusception may also occur in the adult population where it is usually caused by a focal lesion acting as a lead point.

\section{Etiology/Pathophysiology}

- Intussusceptum is pulled further into the distal segment by peristalsis, pulling the mesentery along with it and trapping the vessels

- If not reduced, edema, ischemia and bowel obstruction (usually partial) ensue with necrosis of bowel

- $\quad$ Three etiologies

- Intraluminal : Intraluminal mass (e.g., pedunculated tumor) is pulled forward by peristalsis and brings attached bowel wall with it

- Intramural : Abnormality of bowel wall (e.g., sessile malignancy) causes it not to contract properly, allowing a kink which serves as a lead point 


\section{STUDY CASES}

- Extraluminal : Extraluminal factor (e.g., inflamed appendix) causes area of abnormal peristalsis, allowing a kink which serves as a lead point

- In children

○ Over 90\% have no pathologic lead point- Most thought due to lymphoid hypertrophy following viral infection

○ Less than $10 \%$ due to Meckel's diverticulum, polyp, lymphoma, etc.

Radiographic features: Intussusception can occur essentially anywhere, although in children there is a strong predilection for the ileocolic region.

- ileocolic - most common (75-95\%), presumably due to the abundance of lymphoid tissue related to the terminal ileum and the anatomy of the ileocaecal region

- ileo ileocolic - second most common

- ileoileal and colocolic - uncommon

In adults no such distribution is present as in the vast majority of cases a lead point lesion is present, and thus the location will depend on the location of that lesion.

Anatomy: A loop of bowel infold (and inverts) more distally into the lumen of the bowel and is then carried distally by peristalsis. Approximately $90 \%$ of intussusceptions are ileocolic, in which the terminal ileum is carried through the ileocecal valve into the colon; it may reach the rectum. Idiopathic intussusceptions usually lack an identifiable lead point and occur in children aged 6 months to 2 years. Lymphoid hyperplasia or hypertrophic lymph nodes have been postulated but not proven. Lead points in non idiopathic intussusception may include the following:

- Meckel diverticulum

- Lymphoma of bowel

- Leukemia involving bowel

- Henoch-Schonlein purpura with intramural hemorrhage

- Hemolytic uremic syndrome

- Cystic fibrosis with inspissated bowel content

- Postoperative complication following retroperitoneal surgery

- Post abdominal trauma

- Inflammatory bowel disease

- Polyps

- Peutz-Jeghers syndrome appendix (normal or appendicitis)

- Recent rotavirus immunization

\section{CAUSES}

Children

In the vast majority of cases of intussusception in children, the cause is unknown. Because intussusception seems to occur more often in the fall and winter and because many children with the problem also have flu-like symptoms, some suspect a virus may play a role in the condition. In a few instances, a lead point is identified as the cause of the condition - most frequently Meckel's diverticulum (a pouch in the lining of the small intestine). 


\section{Symptoms}

○ Children:

The first sign of intussusception in an otherwise healthy infant may be sudden, loud crying caused by abdominal pain. Infants who have abdominal pain may pull their knees to their chests when they cry. The pain of intussusception comes and goes, usually every 15 to 20 minutes at first. These painful episodes last longer and happen more often as time passes.

Other frequent signs and symptoms of intussusception include:

- Stool mixed with blood and mucus (sometimes referred to as "currant jelly" stool because of its appearance)

- Vomiting

- A lump in the abdomen

- Lethargy

Less common signs and symptoms include:

- Diarrhea

- Fever

- Constipation

Some infants have no obvious pain, don't pass blood or have a lump in the abdomen. Some older children have pain but no other symptoms.

\section{Clinical Findings}

- Children

○ Cyclical, colicky abdominal pain

○ Vomiting

- "Currant jelly" stools (diarrhea with mucus and blood) or other blood in stool (Classic triad occurs in about $1 / 3$ of patients; most have 2 of the 3 Palpable abdominal mass, often in right upper quadrant)

- Dance's sign: RUQ mass (intussusception) with RLQ empty space (movement of caecum out of normal position)

\section{Imaging Findings}

- Plain radiographs are not sensitive or specific

○ Children

- Soft tissue mass surrounded by a crescent of gas

- Evidence of distal small bowel obstruction

- Absence of or decreased gas in the colon

- Pneumoperitoneum

- May be normal

- Barium enema (diagnostic and therapeutic)- "Coiled spring" appearance $\circ$ Barium in lumen of the intussusceptum and in the intraluminal space

- Ultrasound 
○ Transverse: Target or doughnut sign, with hypoechoic rim (edematous bowel wall) surrounding hyperechoic central area (intussusceptum and associated mesenteric fat)

○ Longitudinal: Sandwich, trident or hayfork sign, with layering of hypoechoic bowel wall and hyperechoic mesentery

○ Oblique: pseudo kidney sign, with hypoechoic bowel wall mimicking the renal cortex and hyperechoic mesentery mimicking the renal fat

- Doppler may help determine viability of the tissue

- Adults: may be less useful, as often cannot identify the pathologic lead point and is most useful when an abdominal mass is palpated

- CT (virtually pathognomonic, most commonly done in adults)

○ Transverse

$\checkmark$ Target sign, with layers of fat and bowel wall visible

$\checkmark$ If enhanced may see mesenteric vessels in the layers and oral contrast in the intraluminal spaces

○ Longitudinal

$\checkmark \quad$ Elongated, sausage-shaped mass with visible layers

○ May be helpful in judging the degree of vascular compromise if fluid or gas collections seen in between the walls of the intussusceptum

○ May or may not see any pathologic lead point.

Treatment and prognosis: In children, intussusceptions can be treated without recourse to surgery in most cases. Using a water soluble medium or air, retrograde pressure can be exerted to reduce the intussusception. If symptoms have been protracted, rectal blood is present, there are signs of peritonitis or enema reduction is unsuccessful then surgical intervention is usually required. With no surgical treatment there can be recurrence rates of up to $30 \%$.

In adults a laparotomy is usually required; especially as in most cases a lead point requiring treatment is present.

- NPO, IV fluids, NG tube if gastric distention

$>$ Children

- Surgical consultation

- Then either reduction with barium, hydrostatic (lactated Ringer's) or air enema, or surgery

\section{Risk Factors}

Risk factors for intussusception include:

- Age. Children are much more likely to develop intussusception than adults are. It's the most common cause of bowel obstruction in children between the ages of 6 months and 3 years.

- Sex. Intussusception more often affects boys.

- Abnormal intestinal formation at birth. A condition present at birth (congenital) in which the intestine doesn't develop correctly (malrotation) also is a risk factor for intussusception.

- A prior history of intussusception. Once you've had intussusception, you're at increased risk to develop it again. 
The advantages of using USWE for reduction of intussusception are:

1. There is no risk of x-ray exposure.

2. It can trace the change of the mass closely, both on transverse and longitudinal scans and can provide a clear echogram: definite criteria of reduction can be obtained.

3. Ileo-ileo-colic intussusception can be diagnosed during reduction.

4. The reduction process can be directly watched in a lit room and the same time changes in the child's general condition, including breathing and abdominal distension can also be assessed.

5. Intestinal perforation during reduction can be accurately and promptly recognised, when the management is simple, reliable and safe.

6. In cases where partial reduction is achieved, the operating time is markedly reduced.

ACKNOWLEDGEMENT: Dr. Jyoti Rai \& Dr. P. Latkar for allowing the use of high end Philips iU 22 ultrasound system. Dr. Gaurav Sharma, CR dept of Radiology for the manuscript.

\section{REFERENCES:}

1. Fiorito ES, Cuestas LAR. Diagnosis and treatment of acute intestinal intussusception with controlled insufflation of air. Pediatrics 1959; 24: 241-244.

2. Phelan E, DeCampo JF, Malechy G. Comparison of oxygen and barium reduction of ileo-colic intussusception. AJR 1988; 150: 1349-1352.

3. Kuha AJ, Benator AM. Intussusception: Hydrostatic pressure equivalents for barium and meglumine sodium diatrizoate. Radiology 1990; 175: 125-126.

4. Finkelstein H. Lehrbuch der sauglingskrankheiten. Zweite halfte, abteilung 1, Berlin, Germany, Fischer's Medicin, 1908, pp 155-157.

5. Heubner 0. Lehrbuch der kinder-heikunde. Erster band. Leipzig, Germany; JA Barth, 1906, pp 219-223.

6. Katz ME, Kohn P. Intussusception reduction 1991: an International survey of Pediatric Radiologists. Pediatr Radiol 1992; 22: 318-322.

7. Meyer JS. The current radiologic management of intussusception: a survey and review. Pediatr Radiol 1992; 22: 322-325.

8. Guo J, Ma X, Zhou Q. Results of air pressure enema reduction of intussusception: 6369 cases in 13 years. J Pediatr Surg 1986; 21: 1201-1203.

9. Jinzhe Z, Yenxia W, Linchi W. Rectal insufflation reduction of intussusception in infants. J Pediatr Surg 1986; 21: 30-32.

10. de Campo JF, Phelan E. Gas reduction of intussusception. Pediatr Radiol 1989; 19: 297-298. ^

11. Gu L, Alton DJ, Daneman A, et al . Intussusception reduction in children by rectal insufflation of air. AJR 1988; 150: 1345-1348.

12. Kim YG, Choi BI, Yeon KM, et al . Diagnosis and treatment of childhood intussusception using real time ultrasonography and saline enema. Preliminary report. J Korean Soc Med Ultrasound 1982; $1: 66-70$.

13. Wang GD, Liu SJ: Enema reduction of intussusception by hydrostatic pressure under ultrasound guidance. J Pediat Surg 1988; 23: 814-818. 
14. Lam AH, Firman K: Value of US including colour Doppler in the diagnosis and management of long standing intussusception. Pediatr Radiol 1992; 22: 112-114.

15. Lim HK, Bae SH, Lee KH, Seo GS, Yoon GS: Assessment of reducibility of ileocolic intussusception in children: usefulness of colour doppler sonography. Radiology 1994; 191: 781-785.

16. Riebel TW, Nasir R, Weber K: US-guided hydrostatic reduction of intussusception in children. Radiology 1993; 188: 513-516.

17. Battenay F, Beasley SW, De Campo JF et al : Intussusception: clinical prediction of outcome of barium reduction. Aust NZ J Surg 1988; 58: 899-902.

18. Pracros JP, Tran-Minh VA, Morin DE, et al : Acute intestinal intussusception in children: contribution of ultrasonography (145 cases). Ann Radiol 1987; 30: 525-530.

19. Stringer MD, Capps SW, Pablot SM: Sonographic detection of the lead point in intussusception. Arch Dis Child 1992; 67: 529-530.

\section{AUTHORS: \\ 1. P.S. Mishrikotkar \\ 2. R.J. Totla \\ 3. Mohd. Ajaz \\ 4. Haseeb \\ 5. Jyoti Rai}

\section{PARTICULARS OF CONTRIBUTORS:}

1. Professor, Department of Radiology, MGM Medical College, Aurangabad.

2. Associate Professor of Surgery, Department of Radiology, MGM Medical College, Aurangabad.

3. Assistant Professor, Department of Radiology, Jalgaon Medical College.
4. Assistant Professor, Department of Radiology, MGM Medical College, Aurangabad.

5. Shanti Imaging Centre, Aurangabad.

\section{NAME ADRRESS EMAIL ID OF THE CORRESPONDING AUTHOR:}

Dr. P.S. Mishrikotkar, Professor of Radiology, MGM Medical College, N-6, CIDC0, Aurangabad.

Email - mishrikotkarss29@rediffmail.com

Date of Submission: 19/07/2013.

Date of Peer Review: 31/07/2013.

Date of Acceptance: 31/07/2013.

Date of Publishing: 12/08/2013. 